\title{
Crystallographic evolution of MAX phases in proton irradiating environments
}

DOI:

10.1016/j.jnucmat.2018.02.008

\section{Document Version}

Accepted author manuscript

Link to publication record in Manchester Research Explorer

\section{Citation for published version (APA):}

Ward, J., Middleburgh, S., Topping, M., Garner, A., Stewart, D., Barsoum, M. W., Preuss, M., \& Frankel, P. (2018). Crystallographic evolution of MAX phases in proton irradiating environments. Journal of Nuclear Materials, 502, 220-227. https://doi.org/10.1016/j.jnucmat.2018.02.008

\section{Published in:}

Journal of Nuclear Materials

\section{Citing this paper}

Please note that where the full-text provided on Manchester Research Explorer is the Author Accepted Manuscript or Proof version this may differ from the final Published version. If citing, it is advised that you check and use the publisher's definitive version.

\section{General rights}

Copyright and moral rights for the publications made accessible in the Research Explorer are retained by the authors and/or other copyright owners and it is a condition of accessing publications that users recognise and abide by the legal requirements associated with these rights.

\section{Takedown policy}

If you believe that this document breaches copyright please refer to the University of Manchester's Takedown Procedures [http://man.ac.uk/04Y6Bo] or contact uml.scholarlycommunications@manchester.ac.uk providing relevant details, so we can investigate your claim.

\section{OPEN ACCESS}




\section{Crystallographic evolution of MAX phases in proton irradiating environments}

Joseph Ward ${ }^{1}$, Simon Middleburgh ${ }^{2}$, Matthew Topping ${ }^{1}$, Alistair Garner ${ }^{1}$, David Stewart ${ }^{3}$, Michel W. Barsoum $^{4}$, and Michael Preuss ${ }^{1}$ and Philipp Frankel ${ }^{1}$

${ }^{1}$ The University of Manchester, Manchester, UK, ${ }^{2}$ Westinghouse, ${ }^{3}$ Rolls-Royce plc., Derby, UK., ${ }^{4}$ Department of Materials Science and Engineering, Drexel University, Philadelphia, USA.

\section{Abstract}

This work represents the first use of proton irradiation to simulate in-core radiation damage in $\mathrm{Ti}_{3} \mathrm{SiC}_{2}$ and $\mathrm{Ti}_{3} \mathrm{AlC}_{2} \mathrm{MAX}$ phases. Irradiation experiments were performed to $0.1 \mathrm{dpa}$ at $350{ }^{\circ} \mathrm{C}$, with a damage rate of $4.57 \times 10^{-6} \mathrm{dpa} \mathrm{s}^{-1}$. The MAX phases displayed significant dimensional instabilities at the crystal level during irradiation leading to large anisotropic changes in lattice parameter, even at low damage levels. The instabilities were accompanied by a decomposition of the Ti-based MAX phases to their binary constituents, TiC. Experimentally observed changes in lattice parameter have been correlated with density functional theory modelling. The most energetically favourable and/or most difficult to recombine defects considered were an M-A antisite $\left(\left\{\mathrm{M}_{\mathrm{A}}: \mathrm{A}_{M}\right\}\right)$, and carbon Frenkel $\left(\left\{\mathrm{V}_{\mathrm{C}}: \mathrm{C}_{\mathrm{i}}\right\}\right)$. It is proposed that antisite defects, $\left\{\mathrm{M}_{\mathrm{A}}: \mathrm{A}_{\mathrm{M}}\right\}$, are the main contributor to the observed changes in lattice parameter. The proposed mechanism reported in this work potentially enables to design MAX phase compositions, which do not favour antisite defect accumulation. In addition, comparison between the experimental results and theoretical calculations shows that a greater amount of residual damage remains in $\mathrm{Ti}_{3} \mathrm{AlC}_{2}$ when compared to $\mathrm{Ti}_{3} \mathrm{SiC}_{2}$ after the same irradiation treatment.

Key words: MAX phases, nuclear, accident tolerant fuel coatings, DFT modelling, x-ray diffraction and proton irradiation.

\section{Introduction}

The harsh environment of light water reactors (LWRs) require materials that can tolerate moderate temperatures $\left(>300{ }^{\circ} \mathrm{C}\right)$, are resistant to aqueous corrosion, and retain their integrity during irradiation. The MAX phases are a unique class of materials, which have been shown to exhibit favourable properties of both ceramics and metals. Similar to metals they are relatively damage tolerant [1], thermally conductive [2], and thermally shock resistant [3]. However, like ceramics, MAX phases also exhibit oxidation resistance [4] and have relatively low densities [3]. They have the general formula $M_{n+1} A X_{n}$, where $M$ stands for an early transition metal, $A$ is an A-group element, and $\mathrm{X}$ is either $\mathrm{C}$ or $\mathrm{N}$. They have a nano-layered structure consisting of binary $\mathrm{MX}_{6}$ octahedra, interleaved with pure A layers. Due to their unique mixture of properties, MAX phases have been suggested as candidates for nuclear in-core nuclear applications, such as accident tolerant fuel coatings (ATFCs) [5,6] and for wear resistant components [3]. The use of MAX phases for ATFCs requires stability throughout normal operation and to allow for increased coping times during loss of coolant accidents (LOCA).

The irradiation resistance of the MAX phases, specifically $\mathrm{Ti}_{3} \mathrm{SiC}_{2}$, was first investigated by Nappé et al. [7]. Samples were irradiated to various fluences using $4 \mathrm{MeV} \mathrm{Au}^{+}$ions at room temperature and grazing incidence $\mathrm{x}$-ray diffraction (XRD) was used to characterise samples before and after irradiation. The relatively large size and low penetration depth of $\mathrm{Au}$ ions and their relatively large size led to amorphisation at high fluences $\left(10^{15} \mathrm{~cm}^{-2}\right)$ [7]. In the same study, similar amorphisation was also observed during a $90 \mathrm{MeV}$ Xe ion irradiation to the same fluence at room temperature. At lower fluences, amorphisation did not occur, however an expansion in the c-lattice parameter was observed. 
More recently, neutron irradiation studies have been conducted on $\mathrm{Ti}_{3} \mathrm{SiC}_{2}, \mathrm{Ti}_{3} \mathrm{AlC}_{2}$, and $\mathrm{Ti}_{2} \mathrm{AlC}$ by Tallman et al. using the $6 \mathrm{MW}$ research reactor at the Massachusetts Institute of Technology Nuclear Reactor Laboratory [8]. This work showed that these MAX phases remained fully crystalline during irradiation of up to $0.1 \mathrm{dpa}$ at $360^{\circ} \mathrm{C}$. However, as much as $50 \mathrm{wt} . \%$ of the $\mathrm{Ti}_{3} \mathrm{AlC}_{2}$ disassociated to TiC. In a later paper by the same authors, the decomposition was more limited [9]. Irradiation gives rise to changes in the MAX phase crystal structure with a decrease in a-lattice parameter and an increase in c-lattice parameter [8]. The formation of basal plane dislocation loops, known as c-loops, have been observed using transmission electron microscopy (TEM) [8,10]. The changes in lattice parameter and the potential presence of dislocation loops have been further confirmed in the MAX phases in numerous other neutron and heavy ion irradiation experiments [11-15]. In contrast, higher temperature $\left(695{ }^{\circ} \mathrm{C}\right)$ neutron irradiation studies show markedly smaller lattice parameter changes [8]. The same is seen during heavy ion irradiations up to $700{ }^{\circ} \mathrm{C}$ by Clarke et al. [16]. It has been suggested that these elevated temperatures provide sufficient energy to allow for point defects to migrate and recombine, thus annealing out damage during irradiation [17]. However, to date, no satisfactory mechanistic explanation has been provided for the observed irradiation-induced lattice changes.

This study focuses on the response of MAX phases, $\mathrm{Ti}_{3} \mathrm{AlC}_{2}$ and $\mathrm{Ti}_{3} \mathrm{SiC}_{2}$, to proton irradiation in order to simulate neutron irradiation. The damage rates attained during proton irradiation can be anywhere between 1 and 3 orders of magnitude higher than neutron irradiations, but lower than typical heavy ion irradiation rates. Proton irradiation has an increased defect production rate, compared to neutron irradiations, whilst producing similar damage defect structures, and is more accessible due to wider equipment availability. Post-irradiation activity is significantly lower compared with neutron irradiation. It has been shown in the literature that proton and neutron irradiations are in good agreement in terms of radiation induced segregation (RIS) and microstructural changes in 300 series stainless steels [18] and $\mathrm{Zr}$ alloys [19,20] despite the differences of cascade size, electronic energy loss and energy spectrum of PKA. For these reasons proton irradiation is increasingly used to simulate neutron irradiation in nuclear materials research.

\section{Experimental Procedure}

\subsection{Materials $\mathrm{Ti}_{3} \mathrm{AlC}_{2}$ and $\mathrm{Ti}_{3} \mathrm{SiC}_{2}$}

The procedure for MAX phase synthesis involves the hot pressing of powders at temperatures of $1300-1500{ }^{\circ} \mathrm{C}$, and under pressure of 30-40 MPa. More details of the fabrication methodology can be found in [21,22]. Samples for proton irradiation were sectioned into matchsticks with dimensions of $2 \times 2 \times 20 \mathrm{~mm}$ using electrical discharge machining (EDM). The samples were subsequently ground and mechanically polished, finishing with $1 / 4 \mu \mathrm{m}$ diamond suspension polishing and oxide polishing suspension prior to irradiation.

\subsection{Proton irradiation}

Proton irradiation was performed at the Dalton Cumbrian Facility at the University of Manchester [23]. The matchstick samples were arranged on an indium bed and secured in place on the temperature controlled stage using a tantalum cover with aluminium foil height adjusters to account for any sample height variations. The indium layer was necessary as a heat sink to improve temperature control. The irradiation was performed using $1.5 \mathrm{MeV}$ protons at $350{ }^{\circ} \mathrm{C}$, with a current density of $0.12 \mu \mathrm{A} \mathrm{mm}{ }^{-2}$. The damage rate was calculated to be $4.57 \times 10^{-6} \mathrm{dpa} \mathrm{s}^{-1}$ to a total of 0.1 dpa $\left(1.438 \times 10^{18}\right.$ protons $\left.\mathrm{cm}^{-2}\right)$ at $60 \%$ of the maximum damage (Bragg peak). This depth represents the material analysed in the current study, non-irradiated and irradiated sample are henceforth referred to as $0 \mathrm{dpa}$ and $0.1 \mathrm{dpa}$. The dose profiles were predicted for the individual MAX phases in 
SRIM using the Detailed Calculation with the Quick Kinchin-Pease calculation run over 1,000,000 ion collisions as suggested by [24]. The displacement thresholds used for SRIM calculations were 25,25 and $28 \mathrm{eV}$ for $\mathrm{Ti}, \mathrm{Si} / \mathrm{Al}$ and $\mathrm{C}$, respectively $[15,25,26]$. The Bragg peak was calculated to be $\sim 18 \mu \mathrm{m}$ sub surface, with a relatively uniform region of $\sim 0.1 \mathrm{dpa}$ being between 9 and $12 \mu \mathrm{m}$. The damage at the Bragg peak is $1.5 \mathrm{dpa}$ and $1.3 \mathrm{dpa}$ for $\mathrm{Ti}_{3} \mathrm{SiC}_{2}$ and $\mathrm{Ti}_{3} \mathrm{SiC}_{2}$, respectively.

\subsection{Characterisation}

$\mathrm{XRD}$ was performed to determine the lattice parameters as well as to ascertain the phase fractions present in the materials both before and after irradiation. A Bruker D8 Discover diffractometer was used with a Co Göbel mirror $(\lambda=1.79 \AA)$, a $0.2 \mathrm{~mm}$ beam slit set up, and a $1.6^{\circ}$ soller slit. This set up was used to attain the highest possible angular resolution utilising both the parallel beam from the Göbel mirror and the small søller slit size. Each scan was performed with a $0.2^{\circ}$ step size and $6 \mathrm{~s}$ exposure over a two-theta range from 30 to $130^{\circ}$. The incident angle was fixed at $18^{\circ}$ and $19^{\circ}$, for $\mathrm{Ti}_{3} \mathrm{AlC}_{2}$ and $\mathrm{Ti}_{3} \mathrm{SiC}_{2}$ respectively. These angles ensure that the maximum x-ray penetration depth is $14 \mu \mathrm{m}$ for each sample, which is within the plateau region of proton-induced damage. Scans on nonirradiated material were taken from the back surfaces of the sample that had not been irradiated. The optics used here gave a beam footprint of $5 \times 2 \mathrm{~mm}$, which kept only the irradiated surface in the $\mathrm{x}$ ray illuminated region. The collected diffraction patterns were processed using a combination of the commercial software packages, Highscore plus and Total pattern analysis solution (TOPAS) V4.2. Highscore plus was used for initial phase identification, while the phase fractions and lattice parameters were attained from TOPAS using Rietveld refinement. Visualization for electronic and structural analysis (Vesta) software V3.3.2 was used to visualise the generated crystallographic information files (cif) from TOPAS refinements.

Scanning electron microscopy (SEM) was performed using a Zeiss Ultra 55 FEG-SEM in order to characterise the MAX phase surface features before and after irradiation. An FEI Sirion FEG-SEM fitted with an electron backscatter diffraction (EBSD) detector was used, in conjunction with Aztec software, to obtain orientation contrast maps. In order to minimise the introduction of damage from sample preparation, samples were not polished post irradiation but instead gently cleaned with an acetone rinse. Scanning transmission electron microscopy (STEM) analysis was used to image the fine, layered structure and was performed on the FEI ChemiSTEM Titan X-FEG microscope, operating at $200 \mathrm{kV}$ and $160 \mathrm{nA}$. Selected area electron diffraction (SAED) was used to perform diffraction studies on individual grains. STEM analysis. SAED patterns were attained using an FEI Tecnai F30 microscope operated at $300 \mathrm{kV}$. Samples for TEM examination were produced from bulk samples using the in-situ lift out technique on an FEI Quanta 3D FEG Dual beam focused ion beam (FIB).

\subsection{Defect modelling}

A density functional theory (DFT) methodology was utilised to explore the effects of point defects on the crystal structure and bonding of both $\mathrm{Ti}_{3} \mathrm{SiC}_{2}$ and $\mathrm{Ti}_{3} \mathrm{AlC}_{2}$ using the Vienna Ab-initio Simulation package (VASP) [27,28]. The GGA-PBE exchange correlation was used with the PAW library available in the VASP package [29]. A supercell of $2 \times 2 \times 1$ unit cells, containing 48 atoms, was used for each phase. While this represents a smaller supercell compared to previous work $[17,30]$, it was deemed suitable as the target of these calculations was to provide a matching of observed experimental behaviour to possible mechanisms rather than a detailed study relating to the defect processes. More detailed examination of defect process can be found in [17,30,31]. A cut-off energy of $400 \mathrm{eV}$ was chosen for all calculations, and the system (including atom positions, cell shape, and volume) was relaxed to an accuracy of $1 \times 10^{-2} \mathrm{eV} / \AA$ using the conjugate gradient algorithm. The self-consistent field convergence stopping criterion was set at $1 \times 10^{-5} \mathrm{eV}$. The spacing of k-points was less than $0.5 \AA^{-1}$. A Gaussian smearing method was used with a width of 0.2 $\mathrm{eV}$. Frenkel and anti-site defects were investigated in both MAX phases. The reason for C-Frenkel 
defects being considered was their low defect energy [17,30,31]. The anti-site defect, specifically an $\mathrm{M}$ residing on an A site and vice versa, was chosen due to its relatively low formation energy but also due to the slow recombination of these defects [17]. It follows that the defects compared in this study are bound C-Frenkel $\left\{\mathrm{V}_{\mathrm{c}}: \mathrm{C}_{\mathrm{i}}\right\}$ and Ti-A antisite defects, $\left\{\mathrm{Ti}_{\mathrm{A}}: \mathrm{A}_{\mathrm{Ti}}\right\}$, where $\mathrm{A}$ is either $\mathrm{Si}$ or $\mathrm{Al}$.

\section{Results}

\subsection{Characterisation}

The phase fractions of each sample were determined by Rietveld refinement of XRD patterns, results are tabulated in Table 1 . Both 312 phases were of high MAX phase purity of $95 \%$; the only impurity phase identified with XRD was TiC. The samples were determined to have a microstructure with fairly homogeneous phase distribution, Figure 1a, and a random crystallographic texture, Figure $1 \mathrm{~b}$.

Table 1: Phase fractions of MAX phases samples before and after proton irradiation at $350{ }^{\circ} \mathrm{C}$. The changes in the a and $\mathrm{c}$ lattice parameter are also listed, together with the results from refinement of the $\mathrm{C}$ z-position and $\mathrm{Ti} 2 \mathrm{z}$-positions.

\begin{tabular}{lccccccccc}
\hline $\begin{array}{l}\text { MAX } \\
\text { phase }\end{array}$ & $\mathrm{dpa}$ & $\mathrm{a}-\mathrm{LP}(\AA)$ & $\begin{array}{c}\mathrm{a}-\mathrm{LP} \\
\text { change } \\
(\%)\end{array}$ & $\mathrm{c}-\mathrm{LP}(\AA)$ & $\begin{array}{c}\mathrm{c}-\mathrm{LP} \\
\text { change } \\
(\%)\end{array}$ & $\mathrm{C}$ z-position & $\mathrm{Ti}_{2}$ z-position & \multicolumn{2}{c}{ Phase fraction (\%) } \\
\cline { 7 - 10 } $\mathrm{Ti}_{3} \mathrm{SiC}_{2}$ & 0 & $3.0675(2)$ & - & $17.671(2)$ & - & $0.0601(5)$ & $0.1371(1)$ & $94.8(2)$ & $5.2(2)$ \\
& 0.1 & $3.0606(3)$ & -0.22 & $17.799(4)$ & 0.72 & $0.0860(6)$ & $0.1363(2)$ & $93.2(3)$ & $6.8(3)$ \\
$\mathrm{Ti}_{3} \mathrm{AlC}_{2}$ & 0 & $3.0717(6)$ & - & $18.525(7)$ & - & $0.0681(9)$ & $0.1270(2)$ & $95.8(8)$ & $4.2(6)$ \\
& 0.1 & $3.0586(8)$ & -0.43 & $18.753(8)$ & 1.22 & $0.0623(1)$ & $0.1286(3)$ & $92.7(5)$ & $7.3(6)$ \\
\hline
\end{tabular}
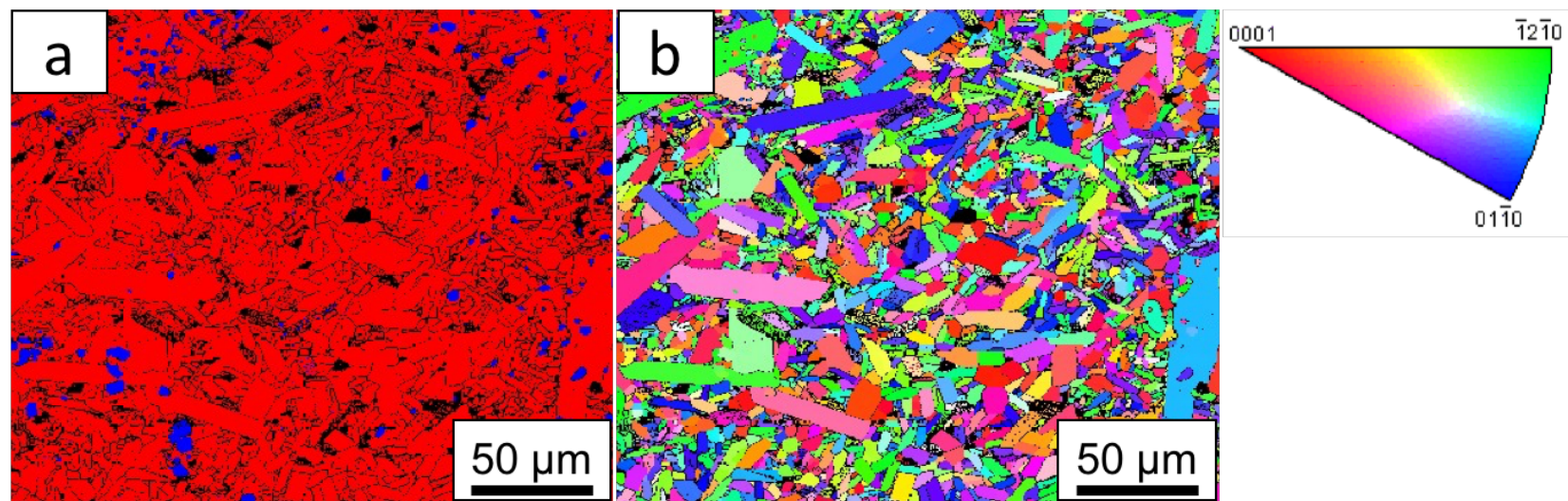

Figure 1: EBSD, a) phase map for the Ti3SiC2 map where blue is TiC, red is Ti3SiC2 and black are unindexed regions. b) orientation contrast map of the $\mathrm{Ti}_{3} \mathrm{SiC}_{2}$ phase obtained with inverse pole figure (IPF) $\mathrm{z}$ legend.

\subsection{Proton irradiation}

SEM images of the MAX phase sample surfaces before, and after irradiation, are shown in Figure 2. Extensive cracking at grain boundaries was observed for both materials after irradiation. STEM HAADF imaging was performed on the irradiated and non-irradiated samples. To ensure imaging of the irradiated samples was performed in the correct region, SRIM profiles (Figure 3a) are matched with an overview of the FIB foil highlighting the 0.1 dpa region (Figure $3 b$ ). 


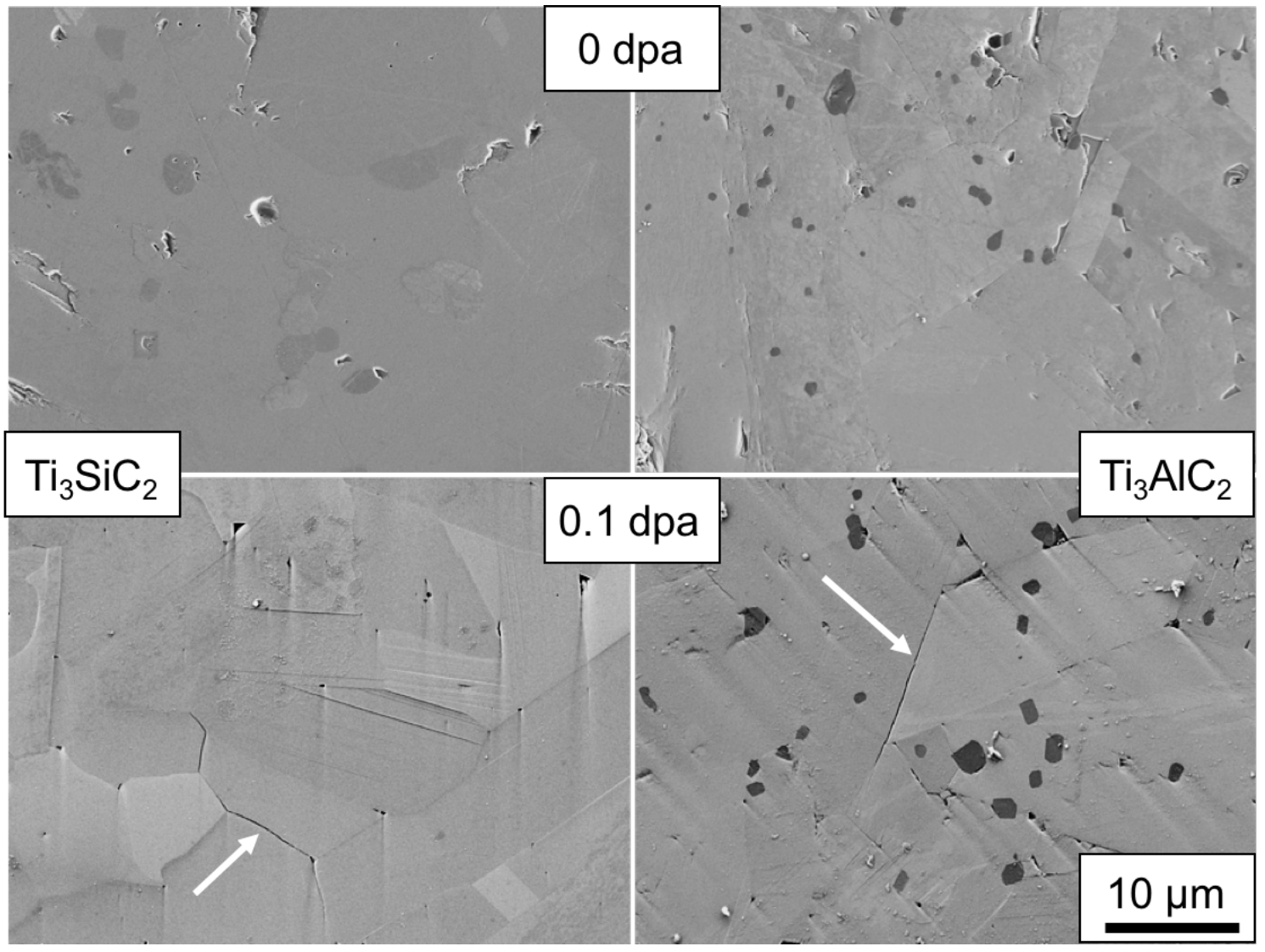

Figure 2: Surface (plan view) SEM micrographs of the MAX phase samples before (top) and after (bottom) proton irradiation to $0.1 \mathrm{dpa}$ at $350{ }^{\circ} \mathrm{C}$. Before irradiation, all samples showed some degree of grain pull-out and pits from sample preparation. After irradiation, all samples showed intergranular cracking (white arrows). The dark regions of both micrographs of $\mathrm{Ti}_{3} \mathrm{AlC}_{2}$ are TiC grains.

Micrographs showing the layered structure of the 0 dpa and 0.1 dpa samples reveal no apparent loss in the layered structure as a result of proton irradiation (Figure 4). The micrograph of the layered structure in the irradiated sample was acquired with in the marked 0.1 dpa region (Figure 3 ).

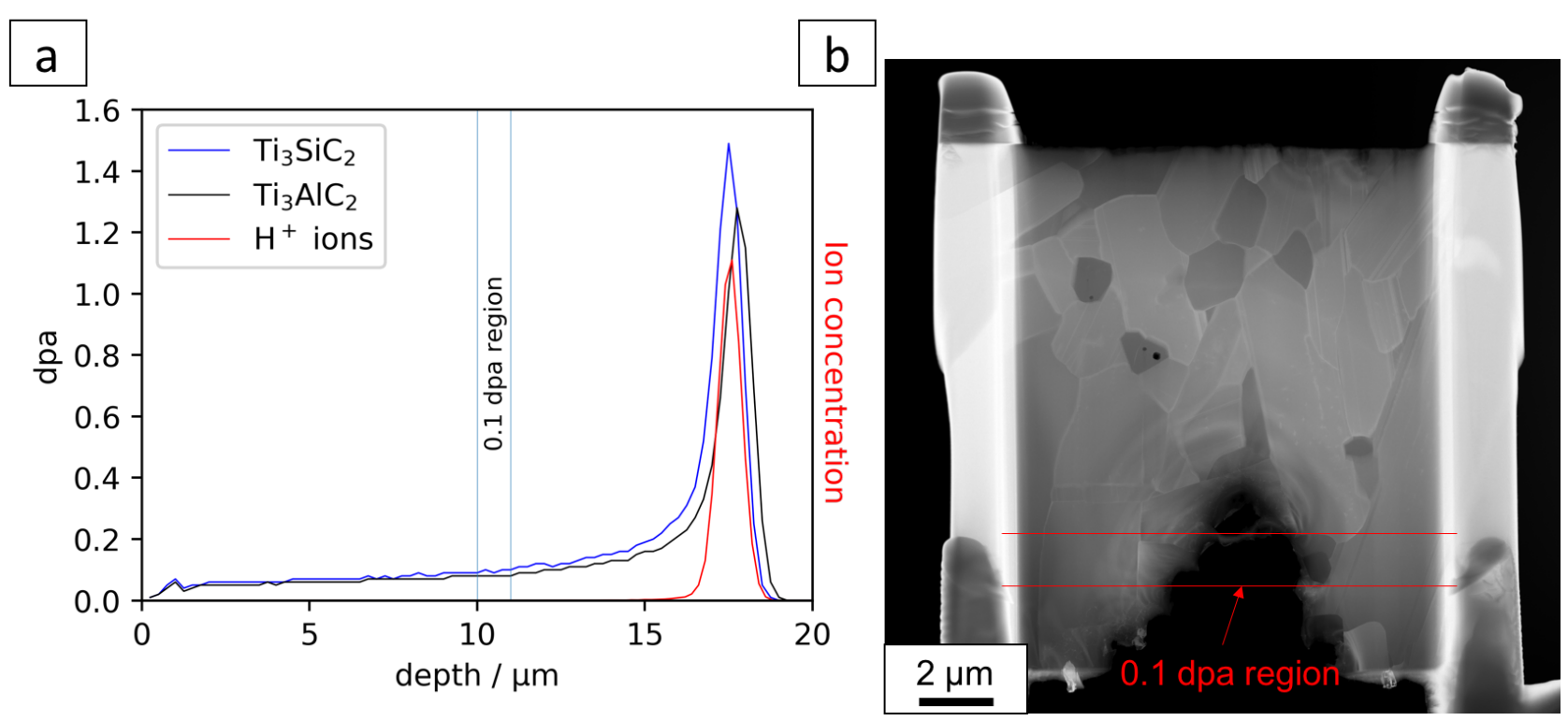

Figure 3: Calculated damage profile and $H$ ion concentration from SRIM with the region corresponding to 0.1 dpa marked (a) and micrograph of the irradiated $\mathrm{Ti}_{3} \mathrm{AIC}_{2}$ sample prepared by FIB milling with the region of 0.1 dpa according to the SRIM profile (b). 
Micrographs showing the layered structure of the 0 dpa (Figure 4a) and 0.1 dpa (Figure $4 \mathrm{~b}$ ) samples reveal no apparent loss in the layered structure as a result of proton irradiation. The samples appeared to remain fully crystalline up to 0.1 dpa proton irradiation at $350{ }^{\circ} \mathrm{C}$. This is demonstrated in Figure $4 \mathrm{~b}$ for $\mathrm{Ti}_{3} \mathrm{AlC}_{2}$, which also shows no $2 \mathrm{D}$ defect structures, such as dislocation loops, in the irradiated sample. SAED patterns of the same region, (inset in Figure 4), were used to measure the c-lattice parameter for both conditions which was found to increase from $18.4 \AA$ to $18.7 \AA$ after irradiation. Hence, the c-lattice parameter appears to have increased. XRD analysis further confirmed such clattice parameter change as a result of irradiation for both compositions.

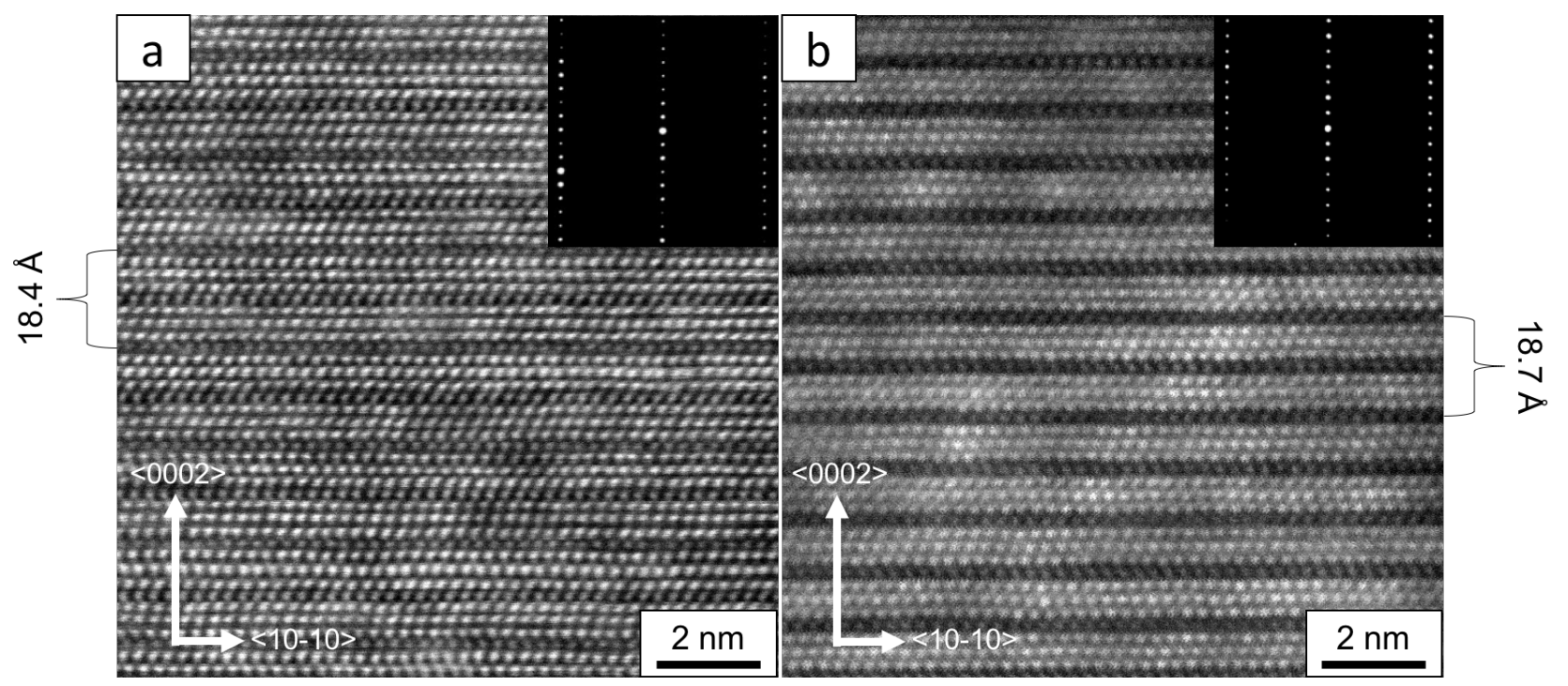

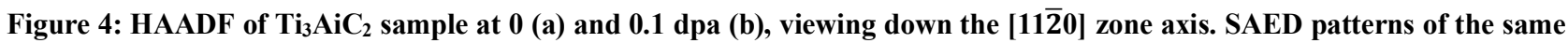
region are inset in the top right-hand part of each image.

The c-lattice parameter measured by XRD was $18.53 \AA$ and $18.75 \AA$ for 0 dpa and $0.1 \mathrm{dpa}$, respectively, thus in good agreement with the SAED results. Typical diffraction patterns from a nonirradiated and irladiated sample of $\mathrm{Ti}_{3} \mathrm{SiC}_{2}$ are shown in Figure 5. Changes in lattice parameter are tabulated in Table 1. The degree of change in lattice parameter is represented as pseudo strain, which is calculated using the following equation:

$$
\operatorname{strain}(\%)=\left(\frac{\left(a_{i r r}-a_{\text {non }}\right)}{a_{\text {non }}}\right) \times 100
$$

Equation 1

where $a_{i r r}$ and $a_{n o n}$ are the lattice parameter of the irradiated sample and non-irradiated sample, respectively. Post-irradiated samples showed anisotropic dimensional changes on the crystallographic level, with reduction in a-lattice parameter and increase in c-lattice parameter. Changes in phase fraction were also observed following irradiation (Table 1). The $\mathrm{Ti}_{3} \mathrm{AlC}_{2}$ showed the greatest dissociation to $\mathrm{TiC}$ and the largest crystallographic changes. No extra phases were observed to have formed which could account for the excess $\mathrm{Si} / \mathrm{Al}$ remaining in solid solution with the MAX phase after dissociation. 


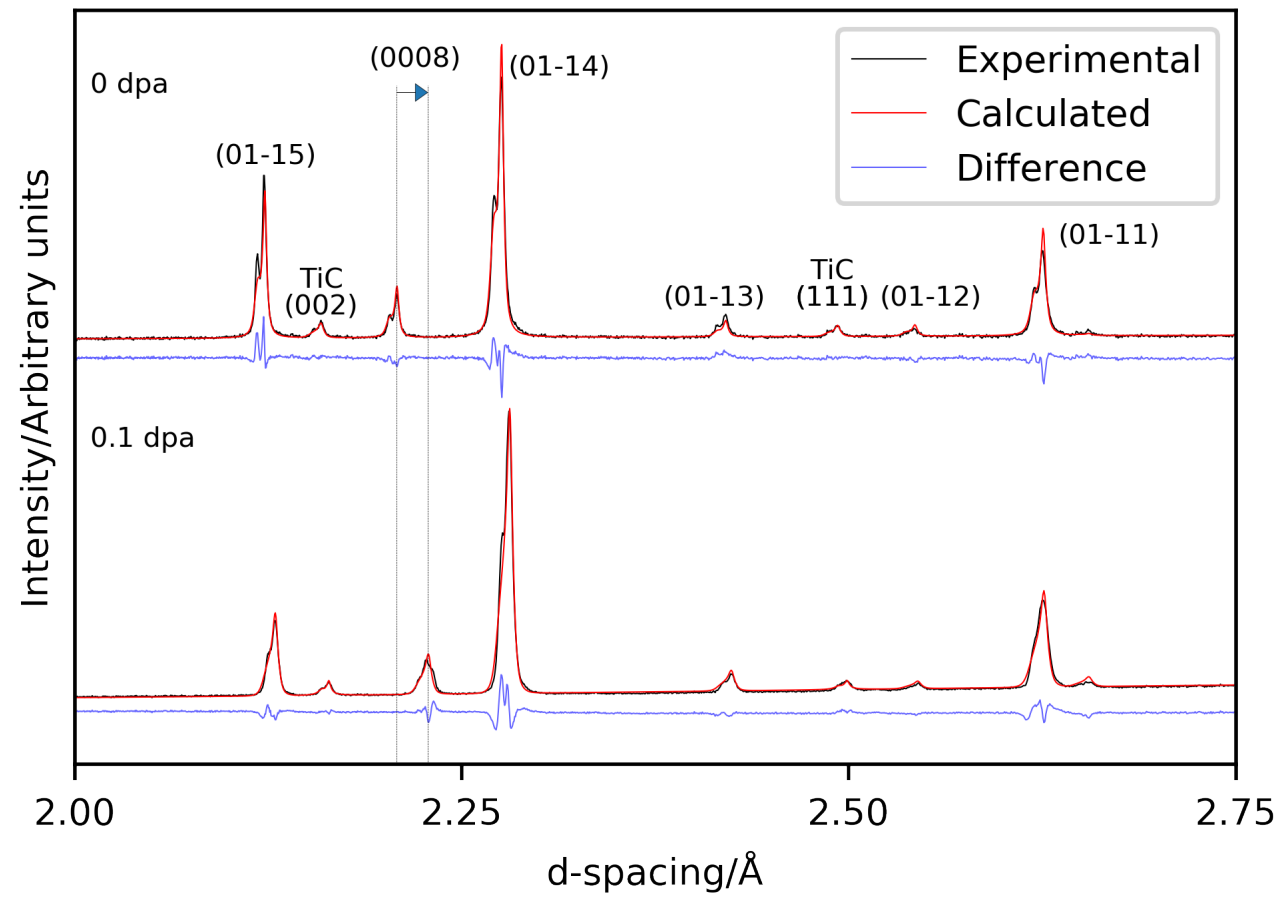

Figure 5: X-ray diffraction pattern for the non-irradiated (top) and irradiated (bottom) $\mathrm{Ti}_{3} \mathrm{SiC}_{2}$. The collected data is shown in black, the calculated Rietveld refinement is shown in red and the difference between the two is shown in blue. The irradiated sample shows peak resolution loss and the $K_{\alpha 1}$ and $K_{\alpha 2}$ are no longer easily distinguished as in the non-irradiated reflections. The large shift in the (008) reflection d-spacing highlights the large changes in lattice parameter observed at low damage levels.

The Rietveld refinement carried out on the XRD patterns using the commercial software package TOPAS allowed the $\mathrm{z}$ Cartesian coordinate of the carbon atoms and $\mathrm{Ti}_{2}$ atoms to refine to the most favourable positions and therefore visualise the crystal structure of the materials before and after irradiation (Figure 6). It can be seen that the $\mathrm{Ti}_{2}$ atoms are those adjacent to the A-layers and their distance increases from the A-layer during irradiation. Similarly, the carbon atoms increase their distance from the central $\mathrm{Ti}$ atoms $\left(\mathrm{Ti}_{1}\right)$ for $\mathrm{Ti}_{3} \mathrm{SiC}_{2}$ while in $\mathrm{Ti}_{3} \mathrm{AlC}_{2}$ the opposite appears to occur with irradiation; the $\mathrm{C}$ atoms shift closer to the $\mathrm{Ti}_{1}$ layer and the $\mathrm{Ti}_{2}$ atoms shift closer to the A-layer. The calculated values for atomic positions are shown in Table 1.

\subsection{Defect modelling}

It has previously been reported that the lowest energy defects in both $\mathrm{Ti}_{3} \mathrm{AlC}_{2}$ and $\mathrm{Ti}_{3} \mathrm{SiC}_{2}$ are $\mathrm{Ti}-\mathrm{A}$ anti-site pairs (where A indicates an A-layer atom), C- Frenkel defects, and A-site Frenkel defects [17], which the current DFT analysis corroborates. C-Frankel defects are C interstial defects which reside in-between the A-layer in $\mathrm{Ti}_{3} \mathrm{SiC}_{2}$ and either side of the A-layer in $\mathrm{Ti}_{3} \mathrm{AlC}_{2}$. Both components of the A-site Frenkel defects, $\left\{\mathrm{V}_{\mathrm{A}}: \mathrm{A}_{\mathrm{i}}\right\}$, reported in [17], resided within the A-layer and recombination of these defects is predicted to be rapid. Therefore, in this work, A-Frenkel defects that reside outside the A-layer were briefly considered and compared to the C-Frenkel and M-A antisite defects. The CFrenkel and Ti-A antisite pair defects were of significantly lower energy $(>4 \mathrm{eV})$.

Each defect type was added to the supercell and the lattice parameters and atomic positions were permitted to relax. The resulting unit cells from the defect simulations have been visualised using Vesta software and are shown in Figure 6. 


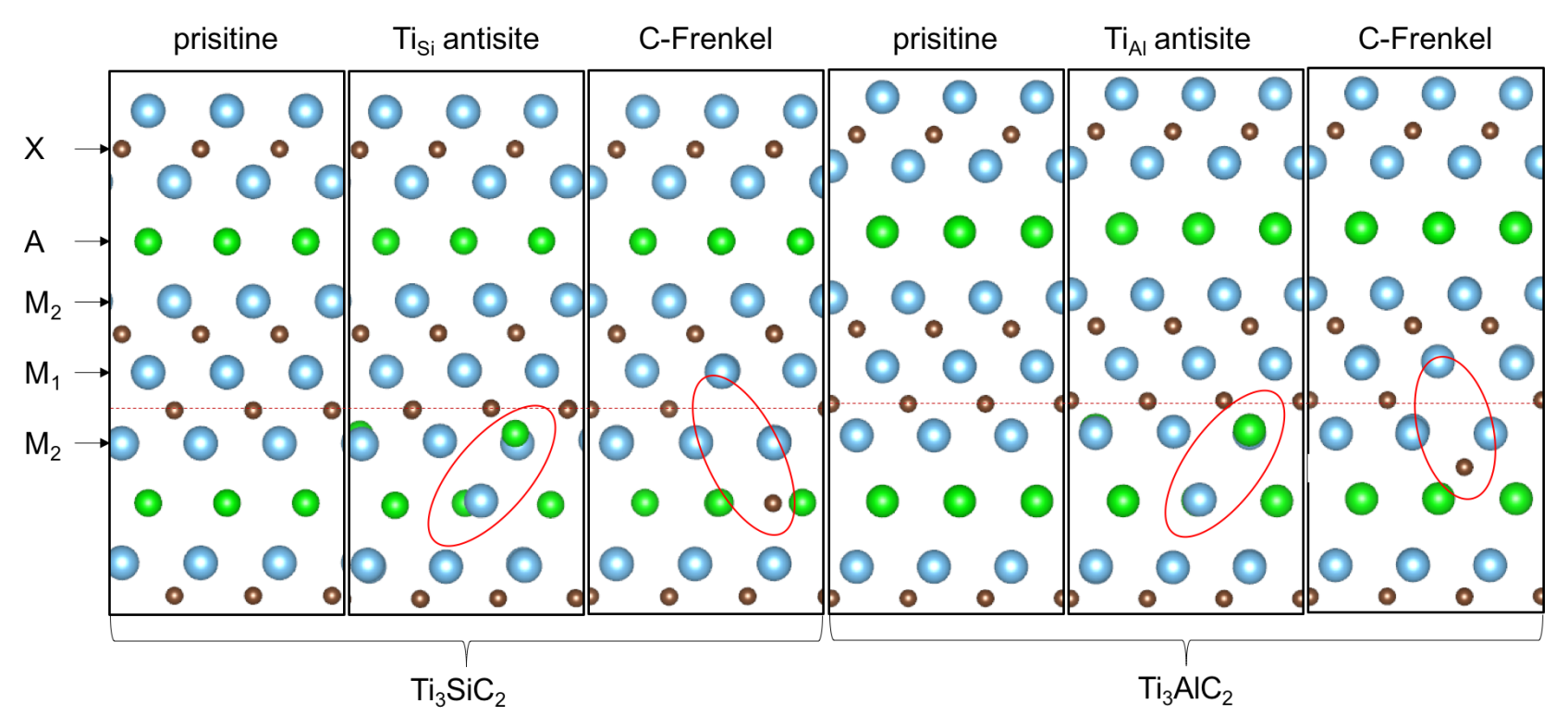

Figure 6: Visualisation of the $\mathrm{Ti}_{3} \mathrm{AlC}_{2}$ unit cells down the $<11 \overline{2} 0>$ zone axis from both modelling and experimental data. The starting unit cells (pristine and $0 \mathrm{dpa}$ ) are compared to the point defect models and after 0.1 dpa proton irradiation. The dotted lines are included to aid in visualising the shift in carbon position.

The resultant changes in lattice parameter due to each type of bound defect are tabulated in Table 2 and are shown graphically in Figure 7. The C-Frenkel defects in $\mathrm{Ti}_{3} \mathrm{SiC}_{2}$ resulted in an expansion both in a and c-lattice parameters, whilst the antisite defects caused a contraction in the a-lattice parameter and expansion in c-lattice parameter. $\mathrm{In}_{\mathrm{Ti}} \mathrm{AlC}_{2}$ both defects cause a reduction in a-lattice parameter and an expansion in c-lattice parameter, in agreement with the experimental results. The defect concentration for both the anti-site defects and Frenkel pairs in both $\mathrm{Ti}_{3} \mathrm{SiC}_{2}$ and $\mathrm{Ti}_{3} \mathrm{AlC}_{2}$ was $4.2 \%$ ( 2 defects per 48 atomic sites).

Table 2: Changes in lattice parameter and unit cell volume introduced due to selected defects within the $\mathrm{Ti}_{3} \mathrm{SiC}_{2}$ and $\mathrm{Ti}_{3} \mathrm{AlC}_{2}$ MAX phases. The DFT modelling has revealed that in $\mathrm{Ti}_{3} \mathrm{SiC}_{2}$ the antisite defect causes a decrease in a-lattice parameter and an increase in c-lattice parameter, whilst the $C_{i}$ results in an expansion of both a and c-lattice parameters. In $\mathrm{Ti}_{3} \mathrm{AlC}_{2}$, both defects result in an increase in c-lattice parameter and a decrease in a-lattice parameter.

\begin{tabular}{|c|c|c|c|c|c|c|c|c|c|}
\hline \multicolumn{10}{|l|}{$\mathrm{Ti}_{3} \mathrm{SiC}_{2}$} \\
\hline & $0 \mathrm{dpa}$ & $0.1 \mathrm{dpa}$ & change & pristine & antisite & change & pristine & Frenkel & change \\
\hline$a-\operatorname{LP}(\AA)$ & 3.068 & 3.061 & $-0.22 \%$ & 3.068 & 3.058 & $-0.33 \%$ & 3.068 & 3.079 & $0.36 \%$ \\
\hline c-LP(Å) & 17.67 & 17.80 & $0.72 \%$ & 17.62 & 17.85 & $1.33 \%$ & 17.62 & 17.69 & $0.43 \%$ \\
\hline $\operatorname{Vol}\left(\AA^{3}\right)$ & 144.0 & 145.1 & $0.76 \%$ & 143.55 & 144.53 & $0.68 \%$ & 143.55 & 145.22 & $1.15 \%$ \\
\hline c/a ratio & 5.76 & 5.82 & $1.04 \%$ & 5.74 & 5.84 & $1.74 \%$ & 5.74 & 5.75 & $0.17 \%$ \\
\hline
\end{tabular}

\begin{tabular}{|c|c|c|c|c|c|c|c|c|c|}
\hline \multicolumn{10}{|c|}{$\mathrm{Ti}_{3} \mathrm{AlC}_{2}$} \\
\hline & $0 \mathrm{dpa}$ & $0.1 \mathrm{dpa}$ & change & pristine & antisite & change & pristine & Frenkel & change \\
\hline a-LP (Â) & 3.072 & 3.059 & $-0.43 \%$ & 3.071 & 3.063 & $-0.28 \%$ & 3.071 & 3.067 & $-0.13 \%$ \\
\hline c-LP(Å) & 18.53 & 18.74 & $1.22 \%$ & 18.51 & 18.67 & $0.84 \%$ & 18.51 & 18.61 & $0.50 \%$ \\
\hline $\operatorname{Vol}\left(\AA^{3}\right)$ & 151.5 & 151.7 & $0.14 \%$ & 151.2 & 151.7 & $0.29 \%$ & 151.2 & 151.6 & $0.24 \%$ \\
\hline c/a ratio & 6.03 & 6.13 & $1.66 \%$ & 6.03 & 6.10 & $1.16 \%$ & 6.03 & 6.07 & $0.66 \%$ \\
\hline
\end{tabular}



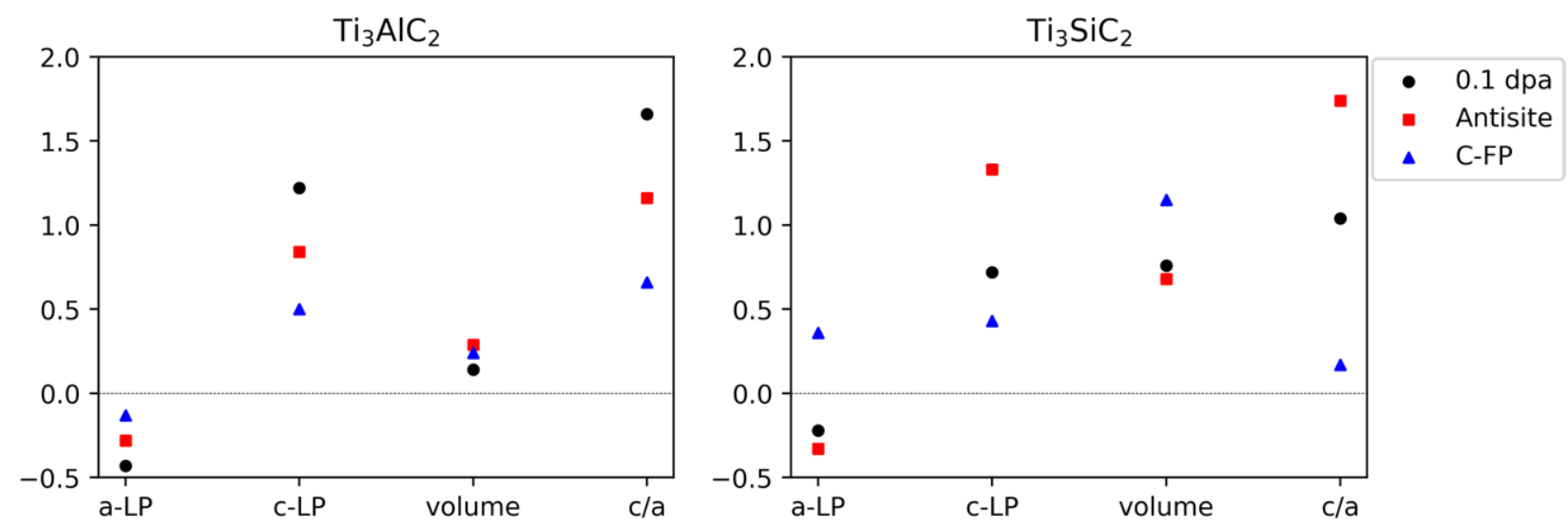

Figure 7: Changes in lattice parameters, unit cell volume and c/a ratio measured or calculated due to the most likely defects within $\mathrm{Ti}_{3} \mathrm{SiC}_{2}$ and $\mathrm{Ti}_{3} \mathrm{AlC}_{2}$ from Table 2 shown graphically.

\section{Discussion}

The changes in lattice parameter measured in both $\mathrm{Ti}_{3} \mathrm{SiC}_{2}$ and $\mathrm{Ti}_{3} \mathrm{AlC}_{2}$ are in agreement with previous work using neutron and heavy ion irradiation, in that there is an increase in c-lattice parameter and a decrease in a-lattice parameter [7,8,10,11,13,14,25,32-36]. The crystallographic instabilities are accompanied by a decomposition of the MAX phase to their binary counterpart; TiC, in agreement with previous observations [8,12,32]. It should be noted that, while $\mathrm{H}$ ions are used for the irradiation discussed, the presence of implanted $\mathrm{H}$ is not considered to be significant to the observations made in this study. Calculations from SRIM (Figure 3) suggest that the vast majority of $\mathrm{H}$ ions would be confined to the Bragg peak region $(\sim 18 \mu \mathrm{m})$, i.e. distant to the material studied here $(<12 \mu \mathrm{m}$ depth). Furthermore, due to the high thermal gradient from sample surface to the cooled back face, which is in contact with the indium heat sink, $\mathrm{H}$ migration would likely be directed away from the irradiated region of the sample. The incidence angle for x-ray diffraction was carefully chosen to avoid the Bragg peak and thereby the region of highest hydrogen content. We are therefore confident that the presence of $\mathrm{H}$ in the structure is not a factor in the observations discussed here.

The anisotropic change in crystal dimensions is believed to be the cause of inter-granular cracking observed after irradiation (Figure 2). Similar cracking behaviour has previously been observed in MAX phases after ion [16] and neutron irradiation [10]. No amorphisation or significant structure change was observed in the XRD patterns, in agreement with the similar appearance of the HAADF images before and after irradiation in Figure 4. Whilst the SAED patterns of these regions are similar, they show an increase in c-lattice parameter, which suggests the presence of point defects that cannot be resolved in the images. The absence of dislocation loops after proton irradiation is puzzling considering they were observed in this material after neutron irradiation [10] to the same dpa value and were also observed in heavy ion irradiation [16], despite very high dose rates. The observation of lattice parameter changes without presence of any defect structures suggests that point defects are the cause of lattice parameter changes. Furthermore, defect structures are of little concern if the material is unable to accommodate point defect induced strains. Therefore, a knowledge of the effects of point defects on the crystal structure is required.

The interaction of high energy protons with the MAX phase causes atoms to be displaced from their original sites, forming Frenkel pairs. The displaced atoms can either displace another atom and reside in the vacant atomic position or form an interstitial defect. In reality, both scenarios are likely to occur simultaneously, creating a mix of antisites, interstitials and vacancies. Although the initial energy of the incoming proton is of high enough energy to create any defect, the energy introduced contributes not only to disorder but also to the thermal energy required to annihilate defects. 
Therefore, defects which have the lowest formation energy are most likely to reside in the material moments after the initial cascade, as defects with high formation energies will be ejected from their site to a lower energy position. Defects that are able to recombine easily will do so and annihilate leaving what are termed residual defects in the material. The defects produced during irradiation have been modelled to examine their stability and migration energies [30,31,37].

Comparing the predicted DFT lattice parameter changes with values measured by XRD (Table 2), suggest that the changes in $\mathrm{Ti}_{3} \mathrm{SiC}_{2}$ are due to $\left\{\mathrm{Ti}_{\mathrm{Si}}: \mathrm{Si}_{\mathrm{Ti}}\right\}$ antisite defects as no other defect type was observed to result in a contraction in the a-lattice parameter value. Although the defect energy of the $\left\{\mathrm{Ti}_{\mathrm{Si}}: \mathrm{Si}_{\mathrm{Ti}}\right\}$ antisite defect is higher than for C-Frenkel $\left(4.29 \mathrm{eV}\right.$ and $3.54 \mathrm{eV}$, respectively for $\mathrm{Ti}_{3} \mathrm{SiC}_{2}$ and $2.68 \mathrm{eV}$ and $2.20 \mathrm{eV}$, respectively for $\mathrm{Ti}_{3} \mathrm{AlC}_{2}$ ), it is expected that the antisite defect will be the dominant residual defect due to it having a lower mobility compared to the C-Frenkel defects. The change in the lattice parameters of the experimental and simulated structures can be used to estimate the concentration of defects in the experimentally irradiated material. Assuming that there is a nearlinear response of the lattice parameter with defect concentration, the extrapolated concentration for the a-lattice parameter is $2.8 \%$ while the extrapolated concentration that for the c-lattice parameter is $2.3 \%$ (the simulated supercell had a defect concentration of $4.2 \%$ ).

The change in lattice parameters observed experimentally in $\mathrm{Ti}_{3} \mathrm{AlC}_{2}$ also appears to suggest that Ti$\mathrm{Al}$ antisite defects are a likely mechanism for irradiation damage in this MAX phase composition. In a similar manner to $\mathrm{Ti}_{3} \mathrm{SiC}_{2}$, the defect concentration in the experimental material after 0.1 dpa can be estimated. The extrapolated defect concentration that matches the a-LP is $6.5 \%$ and for the clattice parameter it is $6.1 \%$. These extrapolated defect concentrations are higher than the concentrations estimated for $\mathrm{Ti}_{3} \mathrm{SiC}_{2}$. The higher defect concentration in the $\mathrm{Ti}_{3} \mathrm{AlC}_{2}$ phase compared to the $\mathrm{Ti}_{3} \mathrm{SiC}_{2}$ can be explained by critiquing the relative defect energies of the antisites in both materials. The antisite defects have energies of $4.29 \mathrm{eV}$ and $2.68 \mathrm{eV}$ for $\mathrm{Ti}_{3} \mathrm{SiC}_{2}$ and $\mathrm{Ti}_{3} \mathrm{AlC}_{2}$, respectively. The lower formation energy of the Ti-Al antisite in $\mathrm{Ti}_{3} \mathrm{AlC}_{2}$ can be expected to result in a higher residual population after irradiation, resulting in larger changes to the lattice parameter. The same argument is applicable for the C-Frenkel defects in both MAX phases. C-Frenkel defects energies are $3.54 \mathrm{eV}$ and $2.20 \mathrm{eV}$ for $\mathrm{Ti}_{3} \mathrm{SiC}_{2}$ and $\mathrm{Ti}_{3} \mathrm{AlC}_{2}$, respectively.

Previously, the resistance to amorphisation of MAX phases has been rationalised by a mechanism where antisite defects stabilise the structure [30]. The present simulation and experimental results strongly supports the domination of antisite defect formation although it should be kept in mind that these findings cannot completely rule out the possibility of other defects being present after irradiation and contributing to the observed lattice changes.

After irradiation, the Rietveld refinement of $\mathrm{Ti}_{3} \mathrm{SiC}_{2}$ shows movement of the $\mathrm{C}$ atom $\mathrm{z}$ fractional coordinate. This movement can be explained by the antisite defect pair formation mechanism that also corroborated the experimentally observed changes to the material's lattice parameter. The Si-C bond length is $7 \%$ smaller than the Ti-C bond length measured from DFT predictions, thus explaining the overall shift of $\mathrm{C}$ atoms towards the A-layers. The opposite trend in $\mathrm{C}$ position is seen in $\mathrm{Ti}_{3} \mathrm{AlC}_{2}$ and can be explained by the change in C-Frenkel defect site (also predicted through DFT modelling), now residing either side of the A-layer, which causes an increase in $\mathrm{C}$ distance from the A-layer. Thus, the global changes in unit cell $\mathrm{C}$ positions measured by XRD also agrees with the changes predicted by DFT as a result of irradiation. It can therefore be expected that a mixture of both antisite and C-Frenkel pairs exist post irradiation. The lattice parameter changes in both MAX phases samples can be explained by the anti-site defect alone. Interestingly, when the preferred size of the $\mathrm{C}$-Frenkel defect is either side of the A-layer, such as in $\mathrm{Ti}_{3} \mathrm{AlC}_{2}$, these also show to have the same effect on lattice parameter as observed with XRD. This suggests that dimensional stability of MAX phases in irradiating environments would be better for compositions which promote C-Frenkel pair 
defects to reside within the A-layer, such as in $\mathrm{Ti}_{3} \mathrm{SiC}_{2}$. It is believed that continued proton irradiation would result in the further accumulation of point defects which would agglomerate into the nanotwinned FCC structure seen by Yang et al. [38]. The results from Yang et al. also suggest the strong influence of antisite defects and C-Frenkel defects on the MAX phase structure. The reason for Yang et al. seeing the formation of these TiC structures is the due the higher damages of $\sim 13.7 \mathrm{dpa}$ and $\sim 150 \mathrm{dpa}$. Interestingly, the formation of anti-site pairs, $\mathrm{Ti}_{\mathrm{Si}}$ and $\mathrm{Si}_{\mathrm{Ti}}$, also explain the increase in $\mathrm{TiC}$ observed after irradiation. Yang et al. proposes that there is a transition from chemical order to disorder. Combining this with the phase change from $\mathrm{Ti}_{3} \mathrm{AlC}_{2}$ to $\mathrm{TiC}$ would explain the decomposition to TiC observed by XRD without the formation of a Si-rich phase.

The response of 312 MAX phases to irradiating environments has previously been attributed to the formation of the $\beta-312$ phase $[14,39]$. This $\beta$ phase is similar to the $\alpha-312$ reported in this work, with the exception that the A elements reside in $2 b$ Wyckoff position as opposed to the $2 \mathrm{~d}$ position in $\alpha-$ 312 [3]. The resulting transformation from $\alpha$ to $\beta$ does not affect lattice parameters but only the structure factor of some planes [3]. Simulated diffraction patterns are shown in [3] where relative intensities change for various reflections. The accumulation of point defects will also result in changes of structure factors, thus changing reflection intensities, and would explain the better fitting in some refinements of irradiated diffraction patterns $[8,10,16,25]$.

As the 211 MAX phases also undergo the same lattice changes after irradiation [16], and there is no polymorph of the 211 MAX phases, it is unlikely that a transformation to a $\beta$-phase is the cause of crystallographic changes in the $\alpha$-phase. The 211 MAX phases are likely to experience a similar defect formation mechanism to the $312 \mathrm{MAX}$ phases under irradiation. Correlations can be made with the work by Wang et al, who showed the different responses of $\mathrm{Cr}_{2} \mathrm{AlC}$ and $\mathrm{V}_{2} \mathrm{AlC}$ under ion irradiations [40]. For $\mathrm{Cr}_{2} \mathrm{AlC}$ again the antisite defects $\left(\mathrm{Cr}_{\mathrm{Al}}\right)$ were predicted to be the most energetically stable and their effect on lattice parameters has been shown to display the characteristic changes [13]. The response of other $211 \mathrm{MAX}$ phases, such as $\mathrm{Ti}_{2} \mathrm{AlC}$ and $\mathrm{Ti}_{2} \mathrm{AlN}$, also display similar lattice parameter changes with an increase in c-LP and a contraction of a-LP [8]. This could indicate that the lattice response to irradiation is caused by the same mechanism. The 413 MAX phases would most likely follow a similar trend to the 312 and 211 MAX phases, however the increased amount of MX layers would likely make defect transport more difficult.

The findings reported here, and in previous work, suggest that MAX phases are not suitable for incore nuclear applications below $350^{\circ} \mathrm{C}$. The use of $\mathrm{Ti}_{3} \mathrm{SiC}_{2}$ and $\mathrm{Ti}_{3} \mathrm{AlC}_{2}$ are good examples of the inherent problem with MAX phases in irradiating environments at low temperatures. The layered structure acts as a defect sink but not as a suitable recombination and annihilation site. Zhao et al. reported on the weaker bonding between $\mathrm{Al}$ and $\mathrm{Ti}_{2}$ compared to $\mathrm{Si}_{-} \mathrm{Ti}_{2}$, allowing for lower energy cost for the damaged structure to be re-established [30]. However, this is not seen in experimental irradiation studies where greater changes in lattice parameters are observed for $\mathrm{Ti}_{3} \mathrm{AlC}_{2}$ compared with $\mathrm{Ti}_{3} \mathrm{SiC}_{2}[8,25]$. Instead, the weaker bonding between the $\mathrm{A}$ atom and nearest $\mathrm{M}$ atoms $\left(\mathrm{M}_{2}\right)$ appears to change the location of the favourable $\mathrm{C}$-Frenkel defects. Hence, it can be predicted that tailoring the MAX phase composition would not change the inherent problem of either $\mathrm{M}_{\mathrm{A}}$ or $\mathrm{C}_{\mathrm{i}}$ defects. This is highlighted when considering the difference in bonding between the MAX phases already studied in literature.

In order for the MAX phases to be used in irradiating environments, the operating temperature must be sufficient to anneal defects at a tolerable rate so that lattice changes are kept to a minimum and the integrity of the component can be maintained. A systematic study is required to understand the critical irradiation temperature to avoid crystallographic instabilities. Whilst studies have shown that crystallographic instabilities are reduced at elevated temperatures, mid-range temperature behaviour must be assessed to understand the effects of temperature fluctuations during operation and post- 
operation (i.e. decommissioning). This would allow for a more comprehensive understanding of which particular nuclear applications MAX phases might be suited for. The current findings suggest that MAX phases may have great potential for use in GEN IV reactors, however in should be noted that further work is needed to consider other factors including the reported diffusion of fission products in these conditions [41].

\section{Conclusions}

The results have shown that similar observations to neutron and heavy ion irradiation are seen with proton irradiation of Ti-based MAX phases, namely: anisotropic changes in unit cell dimensions and decomposition of the MAX phase to TiC. This suggests that proton irradiation is a suitable surrogate for neutrons when investigating MAX phases for nuclear applications. DFT modelling has shown that antisite defects in both MAX phases studied here are the most likely contributors to the observed lattice parameter changes seen experimentally with x-ray diffraction. Whilst the effects of other defects are not discounted, the poor migration and annihilation ability of the antisite defects makes them the most likely mechanism for irradiation-induced damage. By combining the experimental observations with the modelling data, we have been able to predict that the residual defect concentration in the $\mathrm{Ti}_{3} \mathrm{AlC}_{2} \mathrm{MAX}$ phase is higher than in the $\mathrm{Ti}_{3} \mathrm{SiC}_{2} \mathrm{MAX}$ phase after the same proton irradiation exposure. This is likely a result of the lower antisite defect formation energy in $\mathrm{Ti}_{3} \mathrm{AlC}_{2}$, which results in a larger population of formed and residual defects under non-equilibrium conditions. Whereas increasing the temperature during irradiation could be a suitable way to avoid accumulation of these defects, it would suggest that MAX phases are inherently not suitable for incore light water reactor applications. The proposal of the antisite defect mechanism resulting in lattice parameter changes allows for future research in the MAX phase field to be directed at compositions which do not form these defects as easily. Furthermore, MAX phase compositions which have CFrenkel defects, that preferably reside either side of the A-layer, will likely experience greater dimensional instabilities. As such, when considering irradiation tolerant MAX phases, those with a shorter distance between $\mathrm{M}_{2}$ and A-layers may be advantageous. DFT modelling of migration energies for antisite defects could be used to direct this choice and find suitable compositions, as it is believed that formation energy alone is not purely indicative of radiation tolerance.

\section{Acknowledgements}

This research is funded by the new nuclear manufacturing (NNUMAN) research grant and Rolls Royce plc. The authors would like to thank Samir de Moraes Shubeita and Paul Wady at the Dalton Cumbrian Facility for their assistance with radiation experimentation. Thanks, should also be paid to Gary Harrison and John Warren at the University of Manchester for their expertise in XRD. Acknowledgement is also paid to the research group carbides for future fission environments (CAFFE), which has helped facilitate this research. Financial support for this research is provided by EPSRC (EP/J021172/1 and EP/M018563/1) and Rolls-Royce plc. Michael Preuss also acknowledges EPSRC funding for his Leadership Fellowship (EP/I005420/1).

\section{References}

[1] M.W. Barsoum, M. Radovic, Mechanical Properties of the MAX Phases, Encylopedia Mater. Sci. Technol. 2 (2004) 1-16.

[2] M.W. Barsoum, T. El-raghy, C.J. Rawn, W.D. Porter, H. Wang, E.A. Payzant, et al., Thermal properties of Ti3SiC2, J. Phys. Chem. Solids. 60 (1999) 429-439.

[3] M.W. Barsoum, MAX Phases: Properties of Machinable Ternary Carbides and Nitrides, Wiley-VCH, Weinheim, Germany, 2013. 
[4] M.W. Barsoum, T. El-raghy, Oxidation of Ti3SiC2 in Air, J. Electrochem. Soc. (1997).

[5] B. Maier, B. Hauch, G. Johnson, K. Sridharan, University of Wisconsin Cold Spray Program for MAX Phase Coating Deposition for ATF Cold Spray Materials Deposition Technology, (2014) 1-9.

[6] I. Younker, M. Fratoni, Neutronic evaluation of coating and cladding materials for accident tolerant fuels, Prog. Nucl. Energy. 88 (2016) 10-18. doi:10.1016/j.pnucene.2015.11.006.

[7] J.C. Nappé, P. Grosseau, F. Audubert, B. Guilhot, M. Beauvy, M. Benabdesselam, et al., Damages induced by heavy ions in titanium silicon carbide: Effects of nuclear and electronic interactions at room temperature, J. Nucl. Mater. 385 (2009) 304-307. doi:10.1016/j.jnucmat.2008.12.018.

[8] D.J. Tallman, E.N. Hoffman, E.N. Caspi, B.L. Garcia-Diaz, G. Kohse, R.L. Sindelar, et al., Effect of neutron irradiation on select MAX phases, Acta Mater. 85 (2015) 132-143. doi:10.1016/j.actamat.2014.10.068.

[9] D.J. Tallman, L. He, J. Gan, E.N. Caspi, E.N. Hoffman, M.W. Barsoum, Effects of neutron irradiation of Ti3SiC2 and Ti3AlC2 in the 121-1085C temperature range, J. Nucl. Mater. 484 (2017) 120-134. doi:10.1016/j.jnucmat.2016.11.016.

[10] D.J. Tallman, L. He, B.L. Garcia-Diaz, E.N. Hoffman, G. Kohse, R.L. Sindelar, et al., Effect of neutron irradiation on defect evolution in Ti3SiC2 and Ti2AlC, J. Nucl. Mater. 468 (2016) 194-206. doi:http://dx.doi.org/10.1016/j.jnucmat.2015.10.030.

[11] C. Ang, C. Silva, C. Shih, T. Koyanagi, Y. Katoh, S.J. Zinkle, Anisotropic swelling and microcracking of neutron irradiated Ti3AlC2-Ti5Al2C3 materials, Scr. Mater. 114 (2016) 7478.

[12] L. Zhang, Q. Qi, L.Q. Shi, D.J. O’Connor, B.V. King, E.H. Kisi, et al., Damage tolerance of Ti3SiC2 to high energy iodine irradiation, Appl. Surf. Sci. 258 (2012) 6281-6287. doi:10.1016/j.apsusc.2012.03.022.

[13] Q. Huang, H. Han, R. Liu, G. Lei, L. Yan, J. Zhou, Saturation of ion irradiation effects in Cr2AlC, Acta Mater. 110 (2016) 1-14. doi:10.1016/j.actamat.2016.03.021.

[14] X. Liu, M. Le Flem, J.L. Béchade, F. Onimus, T. Cozzika, I. Monnet, XRD investigation of ion irradiated Ti3Si0.90A10.10C2, Nucl. Instruments Methods Phys. Res. Sect. B Beam Interact. with Mater. Atoms. 268 (2010) 506-512. doi:10.1016/j.nimb.2009.11.017.

[15] K.R. Whittle, M.G. Blackford, R.D. Aughterson, S. Moricca, G.R. Lumpkin, D.P. Riley, et al., Radiation tolerance of Mn+1AXn phases, Ti3AlC2 and Ti3SiC2, Acta Mater. 58 (2010) 4362-4368. doi:10.1016/j.actamat.2010.04.029.

[16] D.W. Clark, S.J. Zinkle, M.K. Patel, C.M. Parish, High temperature ion irradiation effects in MAX phase ceramics, Acta Mater. 105 (2016) 130-146. doi:10.1016/j.actamat.2015.11.055.

[17] S.C. Middleburgh, G.R. Lumpkin, D. Riley, Accommodation, accumulation, and migration of defects in Ti3SiC2 and Ti3AlC2 MAX phases, J. Am. Ceram. Soc. 96 (2013) 3196-3201. doi:10.1111/jace. 12537.

[18] G.S. Was, J.T. Busby, T. Allen, E.A. Kenik, A. Jensson, S.M. Bruemmer, et al., Emulation of neutron irradiation effects with protons: Validation of principle, J. Nucl. Mater. 300 (2002) 198-216. doi:10.1016/S0022-3115(01)00751-6.

[19] E.M. Francis, A. Harte, P. Frankel, S.J. Haigh, D. Jädernäs, J. Romero, et al., Iron redistribution in a zirconium alloy after neutron and proton irradiation studied by energydispersive X-ray spectroscopy (EDX) using an aberration-corrected (scanning) transmission electron microscope, J. Nucl. Mater. 454 (2014) 387-397. doi:10.1016/j.jnucmat.2014.08.034.

[20] A. Harte, D. Jädernäs, M. Topping, P. Frankel, C.P. Race, J. Romero, et al., The effect of matrix chemistry on dislocation evolution in an irradiated Zr alloy, Acta Mater. 130 (2017) 69-82. doi:10.1016/j.actamat.2017.03.024.

[21] N.J. Lane, S.C. Vogel, M.W. Barsoum, High-temperature neutron diffraction and the temperature-dependent crystal structures of the MAX phases Ti3SiC2 and Ti3GeC2, Phys. Rev. B - Condens. Matter Mater. Phys. 82 (2010) 1-11. doi:10.1103/PhysRevB.82.174109. 
[22] G.W. Bentzel, M. Ghidiu, B. Anasori, M.W. Barsoum, On the interactions of Ti2AlC, Ti3AlC2, Ti3SiC2 and $\mathrm{Cr} 2 \mathrm{AlC}$ with silicon carbide and pyrolytic carbon at $1300^{\circ} \mathrm{C}$, J. Eur. Ceram. Soc. 35 (2015) 4107-4114. doi:10.1016/j.jeurceramsoc.2015.07.029.

[23] P.T. Wady, A. Draude, S.M. Shubeita, A.D. Smith, N. Mason, S.M. Pimblott, et al., Accelerated radiation damage test facility using a $5 \mathrm{MV}$ tandem ion accelerator, Nucl. Instruments Methods Phys. Res. Sect. A Accel. Spectrometers, Detect. Assoc. Equip. 806 (2015) 109-116. doi:10.1016/j.nima.2015.09.088.

[24] R.E. Stoller, M.B. Toloczko, G.S. Was, A.G. Certain, S. Dwaraknath, F.A. Garner, On the use of SRIM for computing radiation damage exposure, Nucl. Instruments Methods Phys. Res. Sect. B Beam Interact. with Mater. Atoms. 310 (2013) 75-80. doi:10.1016/j.nimb.2013.05.008.

[25] Q. Huang, R. Liu, G. Lei, H. Huang, J. Li, S. He, et al., Irradiation resistance of MAX phases Ti3SiC2 and Ti3AlC2: Characterization and comparison, J. Nucl. Mater. 465 (2015) 640-647. doi:10.1016/j.jnucmat.2015.06.056.

[26] H.H. Shen, F.Z. Li, H.B. Zhang, S.M. Peng, X.T. Zu, K. Sun, Effects of Xe+ irradiation on Ti3SiC2 at RT and $500^{\circ}$ C, J. Eur. Ceram. Soc. 37 (2016) 8-11. doi:10.1016/j.jeurceramsoc.2016.08.026.

[27] J. Kresse, G. Hafner, initio J., Phys. Rev. B. 47 (1993) 558-561. doi:10.1103/PhysRevB.47.558.

[28] G. Kresse, From ultrasoft pseudopotentials to the projector augmented-wave method, Phys. Rev. B. 59 (1999) 1758-1775. doi:10.1103/PhysRevB.59.1758.

[29] B.K. Perdew J. P, M. Ernzerhof, Generalized Gradient Approximation Made Simple, Phys. Rev. Lett. 77 (1996) 3865-3868.

[30] S. Zhao, J. Xue, Y. Wang, Q. Huang, Ab initio study of irradiation tolerance for different $\mathrm{Mn}+1 \mathrm{AXn}$ phases: Ti3SiC2 and Ti3AlC2 Ab initio study of irradiation tolerance for different M n11 AX n phases: Ti 3 SiC 2 and Ti 3 AlC 2, J. Appl. Phys. J. Appl. Phys. J. Chem. Phys. Phy. Lett. Appl. Phys. Lett. Phys. Lett. 115 (2014) 23503-104306. doi:10.1063/1.4861384.

[31] J. Xiao, T. Yang, C. Wang, J. Xue, Y. Wang, Investigations on radiation tolerance of $\mathrm{Mn}+1 \mathrm{AXn}$ phases: Study of Ti3SiC2, Ti3AlC2, Cr2AlC, Cr2GeC, Ti2AlC, and Ti2AlN, J. Am. Ceram. Soc. 98 (2015) 1323-1331. doi:10.1111/jace.13450.

[32] C. Ang, S. Zinkle, C. Shih, C. Silva, N. Cetiner, Y. Katoh, Phase stability, swelling, microstructure and strength of $\mathrm{Ti} 3 \mathrm{SiC} 2-\mathrm{TiC}$ ceramics after low dose neutron irradiation, $\mathrm{J}$. Nucl. Mater. (2016). doi:10.1016/j.jnucmat.2016.10.036.

[33] M. Le Flem, X. Liu, S. Doriot, T. Cozzika, I. Monnet, Irradiation damage in Ti3(Si,Al)C2: A TEM investigation, Int. J. Appl. Ceram. Technol. 7 (2010) 766-775. doi:10.1111/j.17447402.2010.02523.x.

[34] J.C. Nappé, I. Monnet, P. Grosseau, F. Audubert, B. Guilhot, M. Beauvy, et al., Structural changes induced by heavy ion irradiation in titanium silicon carbide, J. Nucl. Mater. 409 (2011) 53-61. doi:10.1016/j.jnucmat.2010.12.235.

[35] J.C. Nappé, C. Maurice, P. Grosseau, F. Audubert, L. Thomé, B. Guilhot, et al., Microstructural changes induced by low energy heavy ion irradiation in titanium silicon carbide, J. Eur. Ceram. Soc. 31 (2011) 1503-1511. doi:10.1016/j.jeurceramsoc.2011.01.002.

[36] M.K. Patel, D.J. Tallman, J.A. Valdez, J. Aguiar, O. Anderoglu, M. Tang, et al., Effect of helium irradiation on Ti3AlC2 at $500^{\circ} \mathrm{C}$, Scr. Mater. 77 (2014) 1-4. doi:10.1016/j.scriptamat.2013.12.010.

[37] H. Zhang, J. Wang, J. Wang, Y. Zhou, S. Peng, X. Long, Role of Nanolaminated Crystal Structure on the Radiation Damage Tolerance of Ti3SiC2 : Theoretical Investigation of Native Point Defects, J. Nanomater. (2013) 1-5. http://dx.doi.org/10.1155/2013/831590.

[38] T. Yang, C. Wang, W. Liu, S. Liu, J. Xiao, Q. Huang, et al., Formation of nano-twinned structure in Ti3AlC2 induced by ion-irradiation, Acta Mater. 128 (2017) 1-11. doi:10.1016/j.actamat.2017.01.066. 
[39] T. Yang, C. Wang, C. a. Taylor, X. Huang, Q. Huang, F. Li, et al., The structural transitions of Ti3AlC2 induced by ion irradiation, Acta Mater. 65 (2014) 351-359. doi:10.1016/j.actamat.2013.11.002.

[40] C. Wang, T. Yang, J. Xiao, S. Liu, J. Xue, Q. Huang, et al., Structural Transitions Induced by Ion Irradiation in V2AlC and Cr2AlC, J. Am. Ceram. Soc. 9 (2016) n/a-n/a. doi:10.1111/jace.14118.

[41] W. Jiang, C.H. Henager, T. Varga, H.J. Jung, N.R. Overman, C. Zhang, et al., Diffusion of $\mathrm{Ag}, \mathrm{Au}$ and Cs implants in MAX phase Ti3SiC2, J. Nucl. Mater. 462 (2015) 310-320. doi:10.1016/j.jnucmat.2015.04.002. 